\title{
Alcohol Abuse Scale
}

National Cancer Institute

\section{Source}

National Cancer Institute. Alcohol Abuse Scale. NCI Thesaurus. Code C121285.

A rating scale included in the Behavior Assessment System for Children, College Version, that identifies subjects who eng age in drinking behaviors that have the potential to lead to alcohol abuse and those who experience academic, social, or functional problems due to their alcohol consumption. 